\title{
Subtotal esophageal endoscopic submucosal dissection for long-segment Barrett's esophagus and adenocarcinoma
}

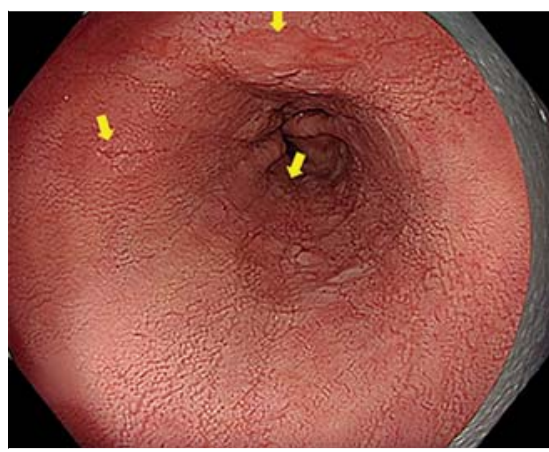

- Fig. 1 Endoscopic view showing longsegment Barrett's esophagus (C12M14), within which biopsies detected esophageal adenocarcinoma in multiple depressed areas, and also within the surrounding mucosa (yellow arrows).

A 73-year-old man was referred to our department with a diagnosis of esophageal adenocarcinoma (EAC) in long-segment Barrett's esophagus (BE), Prague classification C12M14. The long-segment BE extended to the upper thoracic esophagus and non-detectable adenocarcinoma was confirmed in multiple areas of the long-segment BE by random biopsies ( Fig.1). Esophageal endoscopic submucosal dissection (ESD) of the entire area of long-segment BE was therefore performed, with the patient under general anesthesia ( $\triangleright$ Video 1 ). The lesion was resected en bloc ( Fig.2), in 220 minutes, with no adverse events. The total circumferential wound was $16 \mathrm{~cm}$ in length, and steroid injection and polyglycolic acid shielding were performed to prevent stenosis [1]. Histological assessment showed a curative resection, with adenocarcinoma invasion limited to the superficial muscularis mucosa, no lymphovascular invasion, and tumor-free margins ( $\mathbf{F i g . 3}$ ). After the patient's discharge, local steroid injections were performed periodically. Squamous epithelium regeneration was found in the post-ESD area 6 months after ESD, with no recurrence of $\mathrm{BE}$, and no evidence of stenosis ( $\triangleright$ Fig. 4 ).

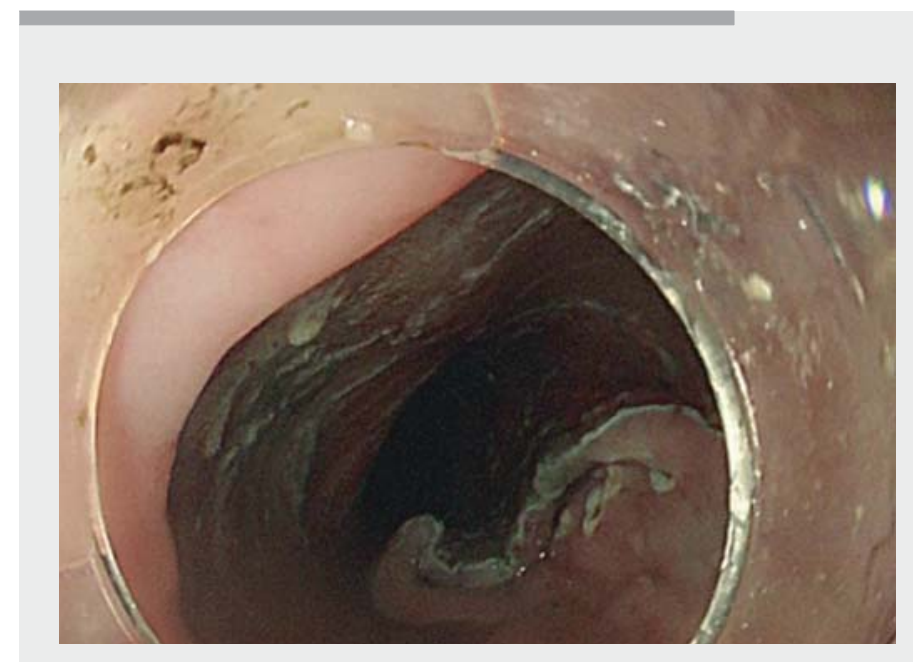

$\checkmark$ Video 1 Subtotal esophageal endoscopic submucosal dissection is performed to treat long-segment Barrett's esophagus and adenocarcinoma.

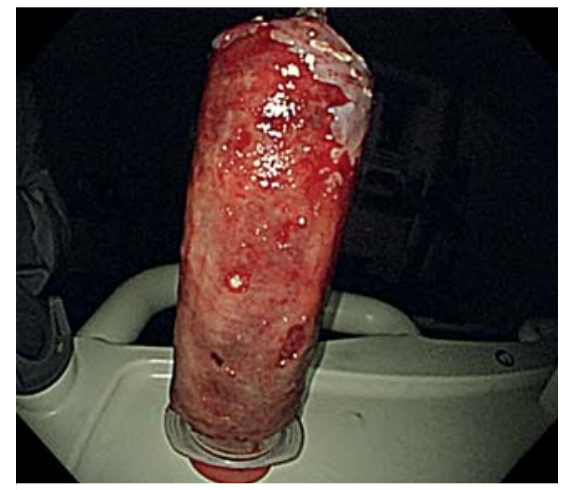

- Fig. 2 Photograph of the full circumferential resection specimen, which was wrapped around a 50-mL syringe.

Currently, radiofrequency ablation, cryotherapy, or hybrid argon plasma coagulation after endoscopic resection are recommended as treatment methods for $\mathrm{BE}$, including where high grade dysplasia is present [2]; intraepithelial carcinoma has also been reported to be controllable by these methods. On the other hand, there is a risk of buried $B E$ due to remnant BE after these endoscopic therapies [3]. In this case, ESD not only resulted in curative treatment of the EAC, confirm-

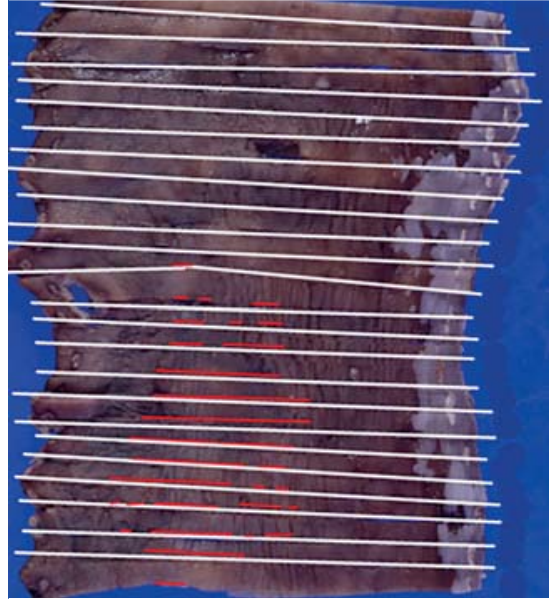

- Fig. 3 Macroscopic appearance of the specimen, which was $111 \times 91 \mathrm{~mm}$ and contained a lesion of $58 \times 31 \mathrm{~mm}$ in size (red lines).

able by histologic assessment following $R 0$ resection, but also resulted in complete en bloc resection of the $B E$, with no risk of remnant BE. Recent advances in endoscopic technology, resection methods, and the development of effective methods of prophylactic treatment for adverse events have enabled safe 

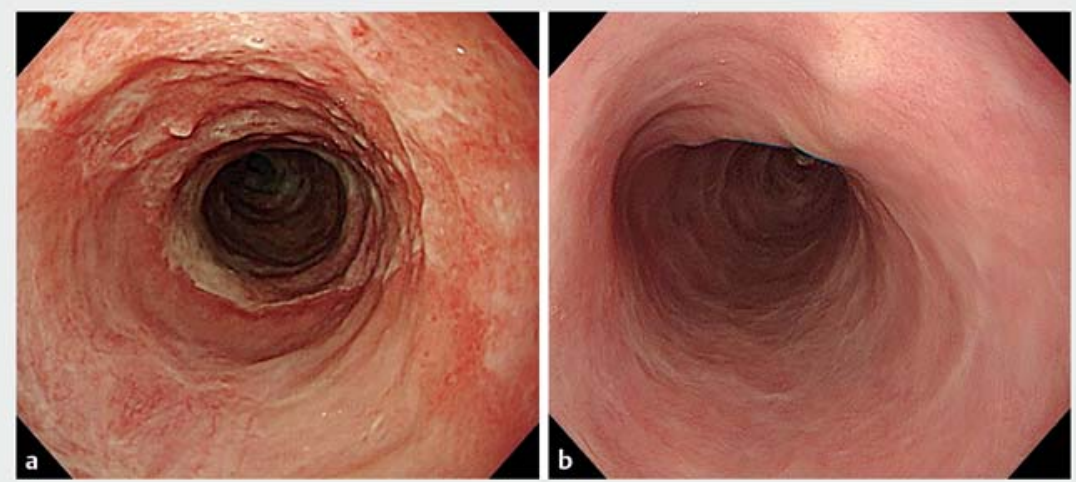

- Fig. 4 Endoscopic appearance on follow-up endoscopies showing: a after 1 month, regeneration of squamous epithelium; $\mathbf{b}$ after 6 months, further regeneration of squamous epithelium, without recurrence of Barrett's esophagus, and with no evidence of stenosis.

and effective extensive esophageal ESD $[4,5]$. Curative treatment with just one session of ESD may become a new standard for treatment of EAC in BE.

Endoscopy_UCTN_Code_TTT_1AO_2AG

Competing interests

The authors declare that they have no conflict of interest.

The authors

Dai Kubota $₫$, Yoshiki Sakaguchi, Sayaka Nagao, Yosuke Tsuji, Mitsuhiro Fujishiro $\odot$ Department of Gastroenterology, Graduate School of Medicine, The University of Tokyo, Tokyo, Japan

\section{Corresponding author}

\section{Yoshiki Sakaguchi, MD, PhD}

Department of Gastroenterology, Graduate School of Medicine, The University of Tokyo, 7-3-1, Hongo, Bunkyo-ku, Tokyo, 113-8655, Japan

sakaguchiy-int@h.u-tokyo.ac.jp

\section{References}

[1] Sakaguchi Y, Tsuji Y, Shinozaki T et al. Steroid injection and polyglycolic acid shielding to prevent stricture after esophageal endoscopic submucosal dissection: a retrospective comparative analysis (with video). Gastrointest Endosc 2020; 92: 1176-1186

[2] Sharma P, Shaheen NJ, Katzka D et al. AGA Clinical Practice Update on endoscopic treatment of Barrett's esophagus with dysplasia and/or early cancer: Expert Review. Gastroenterology 2020; 158: 760-769
[3] Rouphael C, Anil Kumar M, Sanaka MR et al. Indications, contraindications and limitations of endoscopic therapy for Barrett's esophagus and early esophageal adenocarcinoma. Therap Adv Gastroenterol 2020; 13 : 1756284820924209

[4] Abe S, Wu SYS, Ego M et al. Efficacy of current traction techniques for endoscopic submucosal dissection. Gut Liver 2020; 14 : 673-684

[5] Hamada K, Kawano K, Yamauchi A et al. Efficacy of endoscopic submucosal dissection of esophageal neoplasms under general anesthesia. Clin Endosc 2019; 52: 252-257

\section{Bibliography}

Endoscopy 2022; 54: E583-E584

DOI 10.1055/a-1704-7548

ISSN 0013-726X

published online 21.12.2021

(c) 2021. Thieme. All rights reserved.

Georg Thieme Verlag KG, Rüdigerstraße 14,

70469 Stuttgart, Germany

\section{ENDOSCOPY E-VIDEOS}

https://eref.thieme.de/e-videos

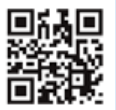

Endoscopy E-Videos is an open access online section, reporting on interesting cases and new techniques in gastroenterological endoscopy. All papers include a high quality video and all contributions are freely accessible online. Processing charges apply (currently EUR 375), discounts and wavers acc. to HINARI are available.

This section has its own submission website at

https://mc.manuscriptcentral.com/e-videos 